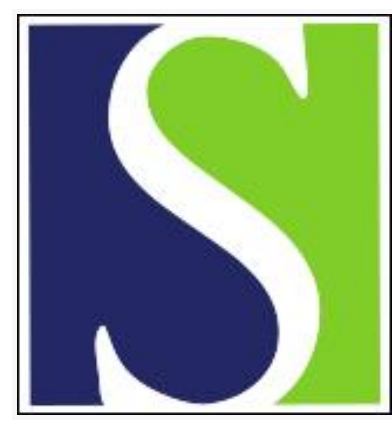

Scand J Work Environ Health 2006;32(3):219-224

https://doi.org/10.5271/sjweh.1002

Issue date: 30 Jun 2006

Occupational skin exposure and hand eczema among dental technicians-need for improved prevention

by Meding B, Wrangsjö K, Hosseiny S, Andersson E, Hagberg S, Torén K, Wass K, Brisman J

Affiliation: Occupational Dermatology, National Institute for Working Life, SE-113 91 Stockholm. birgitta.meding@niwl.se

Key terms: (meth)acrylates; dental technician; dermatitis; epidemiology; grinding dust; hand eczema; hand washing; incidence; occupational skin exposure; prevention; protective gloves; work change

This article in PubMed: www.ncbi.nlm.nih.gov/pubmed/16804625 


\title{
Occupational skin exposure and hand eczema among dental technicians- need for improved prevention
}

\author{
by Birgitta Meding, MD, ${ }^{1}$ Karin Wrangsjö, MD, ${ }^{2}$ Seiran Hosseiny, MD, ${ }^{1,3}$ Eva Andersson, MD, ${ }^{4}$ Stig \\ Hagberg, MSc, ${ }^{4}$ Kjell Torén, MD, ${ }^{4}$ Kristina Wass, ${ }^{4}$ Jonas Brisman, MD ${ }^{4}$
}

\begin{abstract}
Meding B, Wrangsjö K, Hosseiny S, Andersson E, Hagberg S, Torén K, Wass K, Brisman J. Occupational skin exposure and hand eczema among dental technicians-need for improved prevention. Scand J Work Environ Health 2006;32(3):219-224.
\end{abstract}

\begin{abstract}
Objectives The aims of this study were to estimate occupational skin exposure, the use of skin protection, and the incidence of hand eczema among dental technicians.

Methods In a retrospective cohort study, dental technicians $(\mathrm{N}=2139)$ and randomly selected population controls $(\mathrm{N}=2288)$ received a postal questionnaire on occupational skin exposure, protective glove use, and hand eczema, including the year of onset. The response rate was $57 \%$ for the dental technicians and $58 \%$ for the controls.

Results Altogether $80 \%$ of the dental technicians reported skin exposure to uncured (meth)acrylates (MA), and $87 \%$ had skin contact with grinding dust from MA. Thirty-nine percent used protective gloves when handling uncured MA. Twenty-two percent of the currently employed technicians reported participation in obligatory training concerning the handling of thermosetting plastics, and 58\% did not know how long normally used gloves protected the skin against uncured MA. Altogether $48 \%$ of the dental technicians and $30 \%$ of the controls reported more than 10 hand washings a day $(\mathrm{P}<0.001)$. For the dental technicians, the incidence of hand eczema was 8.5 cases/1000 person-years during MA-exposed time. For the controls, the incidence was 3.3. The incidence rate ratio for the men was 3.6 (95\% CI 2.3-5.6), and for the women it was 2.4 (95\% CI 1.7-3.3).

Conclusions The work of dental technicians involves frequent and unprotected exposure to MA and frequent hand washings. Dental technicians have twice the risk of hand eczema than the general population. Efforts to improve skin protection and increase participation in obligatory training about handling thermosetting plastics are important.
\end{abstract}

Key terms dermatitis; epidemiology; grinding dust; incidence; hand washing; (meth)acrylates; protective gloves; work change.

Several publications have focused on occupational skin diseases among dental technicians (1-7). Frequent hand washing and exposure to metals, resins, ceramics, and (meth)acrylates (MA) are reasons for skin problems in the occupation. In questionnaire studies, $28 \%$ of Norwegian dental technicians and $34 \%$ of Swedish ones reported skin symptoms $(4,8)$, and, in a cross-sectional Danish study, the self-reported point prevalence of skin symptoms on the hands of dental technicians was $36 \%$ (9). No data on the incidence of hand eczema have hitherto been published.
Dental technicians have used MA for several decades. The handling of uncured MA involves the risk of skin exposure (10) and can cause contact sensitization, which is well documented in dentistry (11-13). Mürer et al (9) reported that the point prevalence of skin problems on the hands among dental technicians who handled MA was $38 \%$ higher than among those who had never worked with MA. In a German study in which dental technicians with skin symptoms were patch tested, 74\% of the diagnosed contact allergies were to MA monomers (6). Percutaneous absorption of MA (14) and

1 Occupational Dermatology, National Institute for Working Life, Stockholm, Sweden.

2 Occupational and Environmental Dermatology, Karolinska Institutet and Stockholm County Council, Stockholm, Sweden.

3 Department of Dermatology, County Hospital, Gävle-Sandviken, Sweden.

4 Occupational and Environmental Medicine, Sahlgrenska University Hospital, Göteborg, Sweden.

Reprint requests to: Dr B Meding, Occupational Dermatology, National Institute for Working Life, SE-113 91 Stockholm. [Email: birgitta.meding@niwl.se] 
local neurotoxic effects from MA (15) have been demonstrated among dental technicians.

Provisions given by the Swedish Work Environment Authority for thermosetting plastics have been in effect since 1996 (16). Work in the course of activities coming under these provisions can only be directed and done by persons who have undergone special theoretical and practical training concerning the hazards and precautions associated with such work.

Since protective gloves are permeable to MA, there are obvious problems involved in protecting the skin $(17,18)$. Besides gloves can be considered to obstruct the work. The prolonged use of protective gloves is also associated with side-effects such as skin irritation and allergic reactions to natural rubber latex or chemicals added to rubber gloves $(19,20)$.

The aims of this study were to estimate occupational skin exposure, in particular to MA, routines for the use of protective gloves, and the incidence of hand eczema among dental technicians.

\section{Study population and methods}

\section{Study population}

Dental technicians who graduated from dental schools in Sweden between 1949 and 1999 and whose postal addresses were available from the Swedish Register of Persons ( $\mathrm{N}=2139)$, together with randomly selected population controls $(\mathrm{N}=2288)$ with a similar age and gender distribution, received a postal questionnaire in 2001. After two reminders, answers were obtained from 1210 (57\%) dental technicians (535 men and 675 women) and 1316 (58\%) controls (567 men and 749 women). The respondents' mean age was 46 (range 24-77) years for the dental technicians and 45 (range 24-77) years for the controls. Among the 1210 responding dental technicians, 1134 (94\%) had worked as a dental technician after leaving school, 56 (5\%) (21 men and 35 women) had never actually been employed as such, and 20 persons did not report their working history. Six hundred and forty-six (53\%) (307 men and 339 women) reported being currently employed as a dental technician when they answered the questionnaire. Their mean age was 44 (range 24-68) years.

\section{Questionnaire}

The dental technicians were asked about occupational activity after leaving dental school, and the questions concerned work with uncured MA materials, exposure to grinding dust from MA, and glove use during MA work. The dental technicians and controls were asked about exposure to water and detergents, other chemi- cals, and the frequency of hand washing. Questions were also asked about hand eczema, history of childhood eczema, and respiratory symptoms. Results regarding airway symptoms will be published separately. The questions about hand eczema were "Have you ever had hand eczema?", "If yes, what year did the hand eczema first appear?", and "Have you had hand eczema on any occasion during the past 12 months?" The questions regarding the 1-year prevalence of hand eczema, childhood eczema, and hand washing have been validated earlier (21-23).

\section{Nonrespondents}

One hundred and ninety-five each of the dental technicians and the controls who had not returned the questionnaire were randomly selected for a telephone interview. One person interviewed 100 dental technicians and 72 population controls. Phone numbers not available in the directory proved to be the most common cause for those selected not being interviewed. All of the interviewees answered questions about hand eczema, childhood eczema, change of job, and respiratory symptoms. The wording of the questions was the same as in the postal questionnaire. Ninety-three percent of the dental technicians interviewed by phone had worked in the profession after vocational school.

\section{Data analysis and statistics}

Incidence rates were calculated from the number of new cases of hand eczema per person-year under observation (1949 through 2001). Person-years for the dental technicians were calculated from the year they left dental school through 2001 or until they developed hand eczema. Only years with self-reported exposure to MA were included. Population controls contributed with person-years from 20 years of age (ie, the age at which most dental technicians left dental school), through 2001 or until they developed hand eczema. Ninety-five percent confidence intervals $(95 \% \mathrm{CI})$ of the incidence rate ratios were calculated with the test-based method. For comparison between proportions, the chi-square test was used. The study was approved by the Ethics Committee of the Göteborg University.

\section{Results}

\section{Occupational skin exposure}

Reported occupational skin exposure is presented in table 1 . Altogether $80 \%$ of the currently employed dental technicians reported skin exposure to uncured MA, 14\% with daily contact. Skin contact to grinding dust of cured MA materials was reported by $87 \%$; daily contact was 
Table 1. Self-reported occupational skin exposure among the currently employed dental technicians $(\mathrm{N}=646)$ and controls ( $\mathrm{N}=1316)$.

\begin{tabular}{|c|c|c|c|c|c|c|}
\hline \multirow[t]{2}{*}{ Skin exposure } & \multicolumn{3}{|c|}{ Dental technicians } & \multicolumn{3}{|c|}{ Controls } \\
\hline & $\begin{array}{l}\text { Men } \\
(\%)\end{array}$ & $\begin{array}{c}\text { Women } \\
(\%)\end{array}$ & $\begin{array}{l}\text { Total } \\
(\%)\end{array}$ & $\begin{array}{l}\text { Men } \\
(\%)\end{array}$ & $\begin{array}{c}\text { Women } \\
(\%)\end{array}$ & $\begin{array}{c}\text { Total } \\
(\%)\end{array}$ \\
\hline Uncured (meth)acrylates & 85 & $76^{\text {a }}$ & 80 & - & - & - \\
\hline Grinding dust of cured (meth)acrylates & 91 & $84^{\mathrm{a}}$ & 87 & - & - & - \\
\hline Water, detergents, chemicals [except (meth)acrylates] >2hours/day & 7 & $18^{b}$ & $13^{c}$ & 11 & 11 & 11 \\
\hline Hand washing $>10$ times/day & 39 & $56^{b}$ & $48^{d}$ & 29 & 31 & 30 \\
\hline
\end{tabular}

a $\mathrm{P}<0.01$ (men versus women).

b $\mathrm{P}<0.001$ (men versus women).

c $P=0.267$ (dental technicians versus controls).

d $\mathrm{P}<0.001$ (dental technicians versus controls).

stated by $43 \%$. Exposure to MA was more frequent among the men than among the women. Affirmative answers regarding participation in obligatory training in the handling of thermosetting plastics provided by the Swedish Work Environment Authority (16) were given by $22 \%$ of the currently employed dental technicians.

There was no statistically significant difference between the dental technicians and the controls in regard to daily occupational exposure to water, detergents, or chemicals other than MA. However, the dental technicians reported more hand washings per day than the controls did (table 1). Female dental technicians reported more wet work and hand washing than their male colleagues.

\section{Use of protective gloves during (meth)acrylate work}

Of the currently employed dental technicians 39\% reported using protective gloves at work with uncured MA, $29 \%$ of the men and $48 \%$ of the women $(\mathrm{P}<0.001)$. Eight percent used protective gloves for grinding jobs with cured MA materials. The use of double protective gloves was reported by $8 \%$, and the re-use of gloves was admitted by $28 \%$. The glove materials used were $42 \%$ polyvinyl chloride (PVC), 9\% natural rubber latex, $6 \%$ nitrile rubber, and $10 \%$ polyethene (more than one answer possible). Twenty-nine percent did not know what type of gloves they used. The reasons reported for not using protective gloves at work with MA are presented in table 2. Most of the nonglove users claimed that gloves hampered their work (no difference between the genders).

Fifty-eight percent of the dental technicians who used gloves were ignorant of how long normally used gloves protect against MA. Forty percent gave the (correct) answer of 1-10 minutes [dental technicians who had participated in the training in the handling of thermosetting plastics $(64 \%)$ versus those who had not $(31 \%)(\mathrm{P}<0.001)]$.

\section{Hand eczema}

The incidence rate of hand eczema was 8.5 cases $/ 1000$ person-years for the dental technicians during MA-ex-
Table 2. Reported reasons for not using protective gloves for (meth)acrylate work, as given by nonglove-using dental technicians ( $N=234)$ (more than one answer possible).

\begin{tabular}{lc}
\hline Reported reason for not using gloves & $\begin{array}{c}\text { Total } \\
(\%)\end{array}$ \\
\hline Gloves obstruct work & 56 \\
No direct skin contact with (meth)acrylates & 40 \\
Nobody uses gloves at my workplace & 8 \\
No good gloves available at my workplace & 5 \\
Skin symptoms from gloves & 1 \\
The expense & 0 \\
Other reasons & 18 \\
\hline
\end{tabular}

posed worktime (table 3). For the control persons the incidence rate was 3.3 cases $/ 1000$ person-years, giving an incidence rate ratio (IRR) of 2.6 (95\% CI 2.0-3.4), 3.6 (95\% CI 2.3-5.6) for the men and 2.4 (95\% CI 1.73.3) for the women. The female dental technicians had the highest incidence, 10.8 cases/1000 person-years. For the dental technicians the incidence was higher for the time before 1992 in contrast to that of the controls, who had a higher incidence for the later time period (table 3 ). A history of childhood eczema was reported by $12.4 \%$ of the dental technicians and $14.0 \%$ of the controls $(\mathrm{P}=0.26)$.

Among those who reported hand eczema, $63 \%$ of the dental technicians and $53 \%$ of the controls $(\mathrm{P}<0.05)$ had consulted a physician about their eczema. Of all those who had ever worked as a dental technician, $3.1 \%$ reported a change in work due to hand eczema versus $1.7 \%$ of the controls $(\mathrm{P}<0.05)$.

\section{Nonrespondents}

The prevalence of hand eczema was higher among the respondents to the postal questionnaire than among those answering the telephone interview. For the dental technicians, the cumulative prevalence was $20.1 \%$ for the mail respondents and $13.0 \%$ for the telephone respondents $(\mathrm{P}=0.09)$, and for the controls the corresponding values were $13.4 \%$ and $4.2 \%$, respectively $(\mathrm{P}=0.01)$. None of those interviewed by phone had changed jobs due to hand eczema. 
Table 3. Self-reported incidence (cases/1000 person-years) of hand eczema among dental technicians [(meth)acrylate-exposed time] and controls during different time periods.

\begin{tabular}{|c|c|c|c|c|c|c|c|c|c|}
\hline \multirow[t]{2}{*}{ Group } & \multicolumn{3}{|c|}{ 1949-2001 } & \multicolumn{3}{|c|}{ 1949-1991 } & \multicolumn{3}{|c|}{ 1992-2001 } \\
\hline & $\begin{array}{l}\text { Incidence } \\
\text { (cases/ } \\
1000 \text { person- } \\
\text { years) }\end{array}$ & $\begin{array}{c}\text { Cases } \\
(\mathrm{N})\end{array}$ & $\begin{array}{l}\text { Person- } \\
\text { years }\end{array}$ & $\begin{array}{c}\text { Incidence } \\
\text { (cases/ } \\
1000 \text { person- } \\
\text { years) }\end{array}$ & $\begin{array}{c}\text { Cases } \\
(\mathrm{N})\end{array}$ & $\begin{array}{l}\text { Person- } \\
\text { years }\end{array}$ & $\begin{array}{l}\text { Incidence } \\
\text { (cases/ } \\
1000 \text { person- } \\
\text { years) }\end{array}$ & $\begin{array}{l}\text { Cases } \\
(\mathrm{N})\end{array}$ & $\begin{array}{c}\text { Person- } \\
\text { years }\end{array}$ \\
\hline \multicolumn{10}{|c|}{ Dental technicians } \\
\hline Men & 6.8 & 49 & 7184 & 7.2 & 37 & 5170 & 6.0 & 12 & 2014 \\
\hline Women & 10.8 & 59 & 5462 & 11.6 & 41 & 3549 & 9.4 & 18 & 1913 \\
\hline Total & 8.5 & 108 & 12646 & 8.9 & 78 & 8719 & 7.6 & 30 & 3927 \\
\hline \multicolumn{10}{|l|}{ Controls } \\
\hline Men & 1.9 & 30 & 15658 & 1.8 & 19 & 10329 & 2.1 & 11 & 5329 \\
\hline Women & 4.6 & 73 & 16015 & 3.8 & 37 & 9789 & 5.8 & 36 & 6226 \\
\hline Total & 3.3 & 103 & 31673 & 2.8 & 56 & 20118 & 4.1 & 47 & 11555 \\
\hline
\end{tabular}

\section{Discussion}

There are several reasons for avoiding occupational hand eczema. For preventive measures to be successful, knowledge of harmful skin exposure and a positive attitude among users are required. Hand eczema is the most common occupational skin disease, and follow-up studies show that it has a clear tendency to become chronic (24).

This study sought to obtain information on skin exposure and skin protection from the majority of occupationally active dental technicians in Sweden. In addition to questions on exposure, several questions regarding factors of importance for practical prevention were included (eg, attitudes towards gloves and participation in obligatory work-environment training). Information on current and previous exposure to MA was obtained.

Most of the dental technicians, more of the men than the women, reported skin exposure to uncured (meth)acrylates, and almost all of the technicians were exposed to (meth)acrylate grinding dust. The monomers of these chemicals are well documented contact sensitizers $(6,12)$. The allergenic property is restricted to the monomer, but skin reactions to cured grinding dust are probably caused by mechanical skin injuries from sharp dust particles.

Dental technicians, in particular men, reported infrequent glove use when handling MA. Less than half used protective gloves for work with uncured MA, and $90 \%$ had no skin protection when exposed to grinding dust. The main reason for not using gloves was that they hampered the work. The glove material most frequently used was PVC, which is gratifying, considering the possible side-effects of natural rubber latex (20). Protection against $\mathrm{MA}$ is similar for $\mathrm{PVC}$, natural rubber latex, and nitrile rubber and unfortunately lasts only for a few minutes $(17,18)$. This short protection time implies that a frequent change of gloves is necessary to achieve proper skin protection. The knowledge among the dental technicians about protection against MA was insufficient, and a remarkably low participation in the obligatory training regarding the handling of thermosetting plastics (16) was reported (only 22\%). It seems, however, that participation in such training contributes to better knowledge of skin protection. The use of double layers of protective gloves in order to increase the protection against MA has been discussed (18). Whenever possible, nontouch techniques should be preferred when MA is handled, but, in manual dental technicians' work, such techniques are probably difficult to apply fully. It may be possible to increase glove use, if wellfitting, comfortable gloves intended for each worktask (eg, high-quality cotton gloves for protection against grinding dust) are introduced. Regarding the protective capacity of occlusive gloves, new materials are to be expected.

As expected, the incidence of hand eczema was higher among dental technicians than among the general population (IRR 2.6). For both the dental technicians and controls of our study, the incidence was higher among the women than among the men. However, the difference between the genders was less pronounced among the technicians, a finding indicating occupational skin hazards. A higher hand eczema incidence among women is usually attributed to increased total wet exposure, including domestic work and child care (25). In a previous study of hand eczema incidence in the general population of Göteborg, Sweden, with the use of a similar retrospective study design, the highest incidence of hand eczema was found for women between 20 and 30 years of age (26). A well-known risk factor for hand eczema is history of childhood eczema (27). Such a history was reported by similar proportions of the dental technicians and controls in this study and can thus not explain the difference in the hand eczema incidence. It seems that hand eczema gives more consequences in the form of medical consultations and change of jobs among dental technicians than among population controls. This 
situation may reflect problems in working as a dental technician if a person has hand eczema-or maybe more severe hand eczema among dental technicians.

Wet work and hand washing are risk factors for hand eczema. The dental technicians reported the same extent of wet work as the controls but significantly more hand washing. The greater amount of hand washing may contribute to the increased incidence of hand eczema observed among the dental technicians.

Occupational exposure to MA and an increased incidence of hand eczema among dental technicians were confirmed. However, as no patch testing was performed, we do not know what proportion of the hand eczema cases was caused by contact allergy to MA; patch testing is the only method with which to diagnose contact allergy (28). It is probable that most of the hand eczema cases were related to skin irritant exposure, as was found in a previous study of Swedish dentists, another group with frequent occupational exposure to MA (13). As the hand eczema cases were scattered all over the country, a clinical examination was not feasible.

In our study we used a retrospective design. Some interviewees may forget that they had had hand eczema a long time ago, and thus the incidence rates may be underestimated. Such underestimation was found for the controls (table 3 ) in agreement with previous observations of the general population, (26). In contrast, the incidence rate for dental technicians during the previous 10 years was lower than further back in time. A possible improvement in the work environment and an awareness of occupational hazards during the period studied may be responsible for the decreasing incidence of hand eczema among dental technicians.

Since the response rate was rather low, we performed a nonrespondent study. It showed a tendency towards reports of less hand eczema among the telephone respondents than among the postal respondents, among both the dental technicians and the controls. Thus our estimated incidence rate ratios were probably not biased towards an overestimation of the risks.

In conclusion, the study confirms frequent and unprotected skin exposure to MA and frequent hand washings among dental technicians. A more-than-doubled risk of hand eczema than among the general population makes the job of dental technicians a high-risk occupation for hand eczema. Efforts to improve skin protection and to increase participation in obligatory training regarding the handling of thermosetting plastics are important.

\section{Acknowledgments}

We thank Malte Nordqvist for handling the telephone interviews and the questionnaire, Gunborg Lindahl for the data analysis, and Tohr Nilsson for providing facilities to accomplish the study. The study was supported by grants from the Swedish Council for Working Life and the Welander/Finsen Foundation.

\section{References}

1. Estlander T, Rajaniemi R, Jolanki R. Hand dermatitis in dental technicians. Contact Dermatitis. 1984;10:201-5.

2. Rajaniemi R, Tola S. Subjective symptoms among dental technicians exposed to the monomer methyl methacrylate. Scand J Work Environ Health. 1985;11:281-6.

3. Farli M, Gasperini M, Francalanci S, Gola M, Sertoli A. Occupational contact dermatitis in 2 dental technicians. Contact Dermatitis. 1990;22:282-7.

4. Jacobsen N, Hensten Pettersen A. Self-reported occupationrelated health complaints among dental laboratory technicians. Quintessence Int. 1993;24:409-15.

5. Mürer AJL, Poulsen OM, Tüchsen F, Roed-Petersen J. Rapid increase in skin problems among dental technicians trainees working with acrylates. Contact Dermatitis. 1995;33:106-11.

6. Rustemeyer T, Frosch PJ. Occupational skin diseases in dental laboratory technicians (I): clinical picture and causative factors. Contact Dermatitis. 1996;34:125-33.

7. Lee JY, Yoo JM, Cho BK, Kim HO. Contact dermatitis in Korean dental technicians. Contact Dermatitis. 2001;45:13-6.

8. Jacobsen N, Derand T, Hensten-Pettersen A. Profile of workrelated health complaints among Swedish dental laboratory technicians. Community Dent Oral Epidemiol. 1996;24:13844.

9. Mürer AJL, Poulsen OM, Roed-Petersen J, Tüchsen F. Skin problems among Danish dental technicians: a cross-sectional study. Contact Dermatitis. 1995;33:42-7.

10. Liljelind IE, Eriksson KA, Nilsson LO, Jonsson BM, Burström YI. A method for measuring the potential dermal exposure to methyl methacrylate during two different technical work tasks. J Environ Monit. 2005;7:519-23.

11. Hensten-Pettersen A, Jacobsen N. Perceived side effects of biomaterials in prosthetic dentistry. J Prosthet Dent. 1991; 65:138-44

12. Kanerva L, Estlander T, Jolanki R. Occupational skin allergy in dental profession. Dermatol Clin. 1994;12:517-32.

13. Wallenhammar L-M, Örtengren U, Andreasson H, Barregård L, Björkner B, Karlsson S, et al. Contact allergy and hand eczema in Swedish dentists. Contact Dermatitis. 2000;43:1929.

14. Rajaniemi R, Pfäffli P, Savolainen H. Percutaneus absorption of methyl methacrylate by dental technicians. Br J Ind Med. 1989;46:356-7.

15. Seppäläinen AM, Rajaniemi R. Local neurotoxicity of methyl methacrylate among dental technicians. Am J Ind Med. 1984; 5:471-7.

16. National Board of Occupational Safety and Health. Thermosetting plastics provisions of the Swedish National Board of Occupational Safety and Health on thermosetting plastics, together with general recommendations on the implementation of the provisions. Stockholm: National Board of Occupational Safety and Health (Arbetarskyddsstyrelsen), AFS; 1996:4.

17. Andreasson H, Boman A, Johnsson S, Karlsson S, Barregård L. On permeability of methyl methacrylate, 2-hydroxyethyl 
methacrylate and triethyleneglycol dimethacrylate through protective gloves in dentistry. Eur J Oral Sci. 2003;111:529_ 35 .

18. Lönnroth E-C, Wellendorf H, Ruyter IE. Permeability of different types of medical protective gloves to acrylic monomers. Eur J Oral Sci. 2003;111:440-6.

19. Wahlberg JE. Irritation and contact dermatitis from protective gloves-an overview. In Boman A, Estlander T, Wahlberg JE, Maibach HI, editors. Protective gloves for occupational use. $2^{\text {nd }}$ ed. Boca Raton (FL): CRC Press; 2004. p 121-5.

20. Warshaw EM. Latex allergy. J Am Acad Dermatol. 1998; 39:1-24.

21. Meding B, Barregård L. Validity of self-reports of hand eczema. Contact Dermatitis. 2001:45:99-103.

22. Stenberg B, Lindberg M, Meding B, Svensson A. Is the question "Have you had childhood eczema?" useful for assessing atopic eczema in population surveys? Contact Dermatitis. In press.

23. Anveden I, Lidén C, Alderling M, Meding B. Self-reported skin exposure-validation of questions by observation. Contact Dermatitis. In press.

24. Cahill J, Keegel T, Nixon R. The prognosis of occupational contact dermatitis in 2004. Contact Dermatitis. 2004;51:219 26.

25. Meding B. Differences between the sexes with regard to workrelated skin disease. Contact Dermatitis. 2000;43:65-71.

26. Meding B, Järvholm B. Incidence of hand eczema-a population-based retrospective study. J Invest Dermatol 2004; 122:873-7.

27. Coenraads P-J, Diepgen TL. Risk for hand eczema in employees with past or present atopic dermatitis. Int Arch Occup Environ Health. 1998;71:7-13.

28. Wahlberg JE. Patch testing. In: Rycroft RJG, Menné T, Frosch PJ, Lepoittevin J-P, editors. Textbook of contact dermatitis. Berlin: Springer-Verlag; 2001. p 435-68.

Received for publication: 28 October 2005 